\title{
Laparoscopic surgery in a patient with foramen of Winslow hernia due to large uterine fibroids: a case report and literature review
}

\author{
Shusaku Honma ${ }^{1 *} \mathbb{D}$, Takenori Itohara ${ }^{2}$, Seigo Sha ${ }^{2}$ and Hirohiko Onoyama ${ }^{2}$
}

\begin{abstract}
Background: Foramen of Winslow hernia (FWH) is a rare but emergent condition caused by an increase in the foramen diameter, visceral mobility, and intra-abdominal pressure. To the best of our knowledge, this is the first study to report a case of FWH secondary to large uterine fibroids that was successfully treated with laparoscopic surgery.

Case presentation: A 52-year-old woman with large uterine fibroids was diagnosed with FWH. Because of the absence of signs of bowel ischemia and peritonitis, we performed an elective laparoscopic surgery through a 5-port system after bowel decompression using a long intestinal tube. Although foramen of Winslow closure was not performed, her postoperative course was uneventful.
\end{abstract}

Conclusions: Laparoscopic surgery for FWH is considered an extremely effective surgical treatment option because of its safety and efficacy in performing delicate procedures (such as adhesiolysis) with a good magnified field of view.

Keywords: Foramen of Winslow hernia, Internal hernia, Laparoscopy, Uterine fibroid

\section{Background}

The foramen of Winslow is the entryway to the lesser sac located anterior to the inferior vena cava and posterior to the hepatoduodenal ligament [1]. Due to various factors, abdominal contents may protrude through this opening, which results in a foramen of Winslow hernia (FWH). The incidence of FWH is rare, constituting approximately $8 \%$ of internal hernia cases [2]. Although the exact mechanism underlying the pathogenesis of FWH remains unclear, recent reports have shown that increase in the foramen of Winslow diameter $(>3 \mathrm{~cm})$, visceral mobility, and intra-abdominal pressure predisposes patients to FWH [1-5]. Excessive viscera mobility may be due to long bowel mesentery, persistence of the ascending

\footnotetext{
*Correspondence: shomma74@kuhp.kyoto-u.ac.jp

${ }^{1}$ Department of Surgery, Kobe City Medical Center West Hospital, 2-4,

Ichibancho, Nagataku, Kobe, Hyogo 653-0013, Japan

Full list of author information is available at the end of the article
}

mesocolon, bowel malrotations, and large right hepatic lobe [3]. The build-up of intra-abdominal pressure may occur during pregnancy or immediate postprandial states [3].

The most common herniated organ is the small intestine $(60-70 \%)$, followed by the terminal ileum, cecum, and ascending colon (25-30\%) [1]. Although herniation of the gallbladder and transverse colon is extremely rare, a few studies have reported these cases [4, 6-8].

Since FWH often develops rapidly with signs of bowel strangulation and ischemia, urgent surgical treatment is required. Through increasing technological innovation, laparoscopic surgery has been widely used for FWHs [3, $9,10]$.

To the best of our knowledge, no other study has reported a case of FWH caused by uterine fibroids. Here we report a case of FWH secondary to large uterine fibroids that was successfully treated with elective 
laparoscopic surgery under preoperative bowel decompression using a long intestinal tube.

\section{Case presentation}

A 52-year-old woman with unremarkable medical and surgical history presented to the emergency department with intermittent abdominal pain. Physical examinations revealed a soft abdomen with epigastric tenderness without signs of peritonitis. A gently uplifting mass from above the pubis to below the umbilicus was palpated. The patient's white blood cell count was slightly increased to 12,220 cells $/ \mu \mathrm{L}$ (normal value: $4000-8000$ cells/ $\mu \mathrm{L}$ ), and other serum tests (e.g., C-reactive protein and liver enzymes) were within respective reference ranges. Abdominal contrast-enhanced CT showed the presence of large uterine fibroids in the pelvis and herniation of dilated small bowel loops between the portal vein and the inferior vena cava (Fig. 1).

No signs of bowel ischemia or peritonitis were observed. Because abdominal pain was refractory to previously administered medications, we performed elective laparoscopic surgery after bowel decompression using a long intestinal tube on the 19th day of hospitalization.

Laparoscopic surgery was performed using a $12-\mathrm{mm}$ umbilical port and four 5-mm working ports in the bilateral epigastric and hypogastric regions (Figs. 2.and 3). We observed that the small bowel herniated through the foramen of Winslow. Hernia reduction could not be performed simply by pulling out the herniated bowel because of the adhesion between the herniated bowel and intra-omental tissue. Hence, we incised the lesser omentum to open the lesser sac and facilitate adhesiolysis.

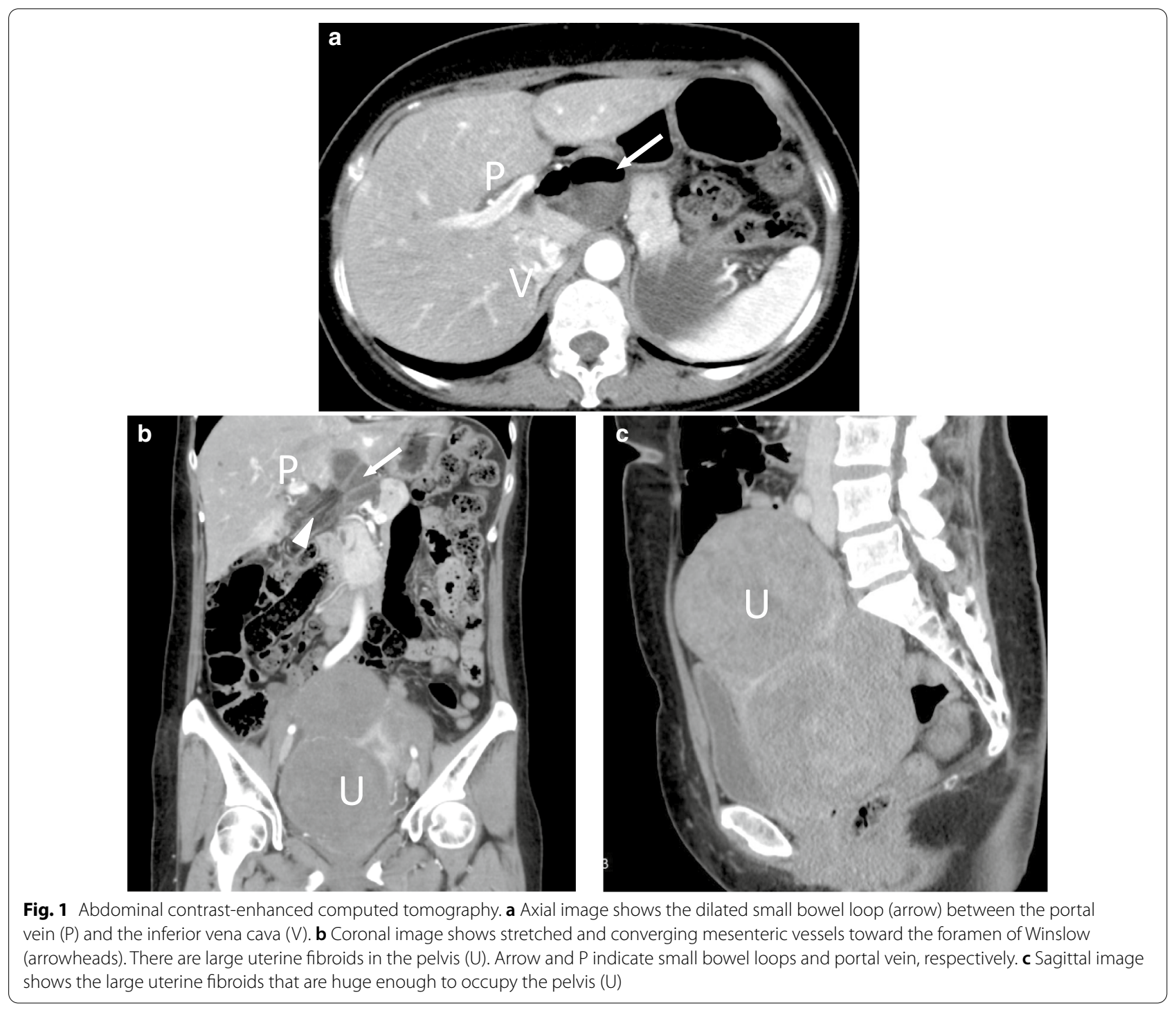




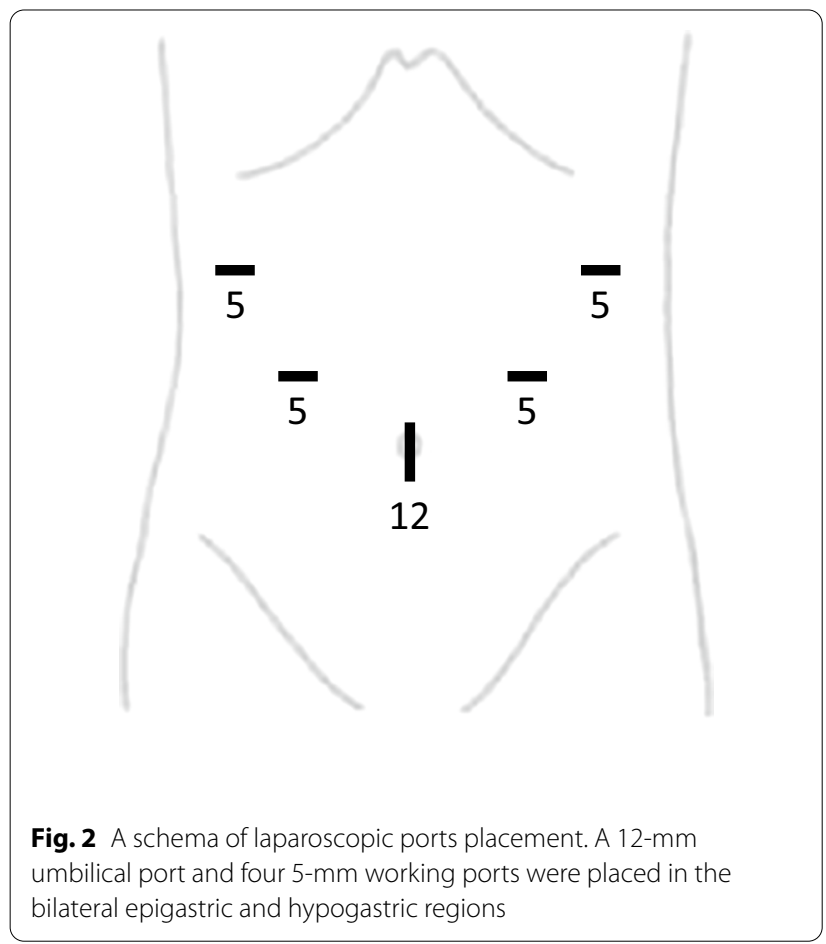

Because the herniated bowel was observed to be viable, bowel resection was not performed. No intestinal malrotation or long bowel mesentery was observed, and closure of the foramen of Winslow was not performed. Nevertheless, there were no postoperative complications and the patient was discharged on postoperative day 6 . No recurrences have occurred after 12 months of follow-up.

\section{Discussion}

The incidence of FWH is rare, constituting approximately $8 \%$ of internal hernia cases [2]. Although the exact mechanism underlying FWH is largely unknown, recent reports have implicated dilation of the foramen of Winslow, excessive viscera mobility (e.g., long bowel mesentery, persistence of the ascending mesocolon, and bowel malrotations), and increase in the intra-abdominal pressure (e.g., pregnancy and immediate postprandial periods) as predisposing factors for the FWH [1-5]. In this case, large uterine fibroids may have caused an increase in the intra-abdominal pressure, as in pregnancy. Currently, based on the available literature, only two FWH cases have been reported in pregnant women $[5,11]$. To the best of our knowledge, this is the first case report of
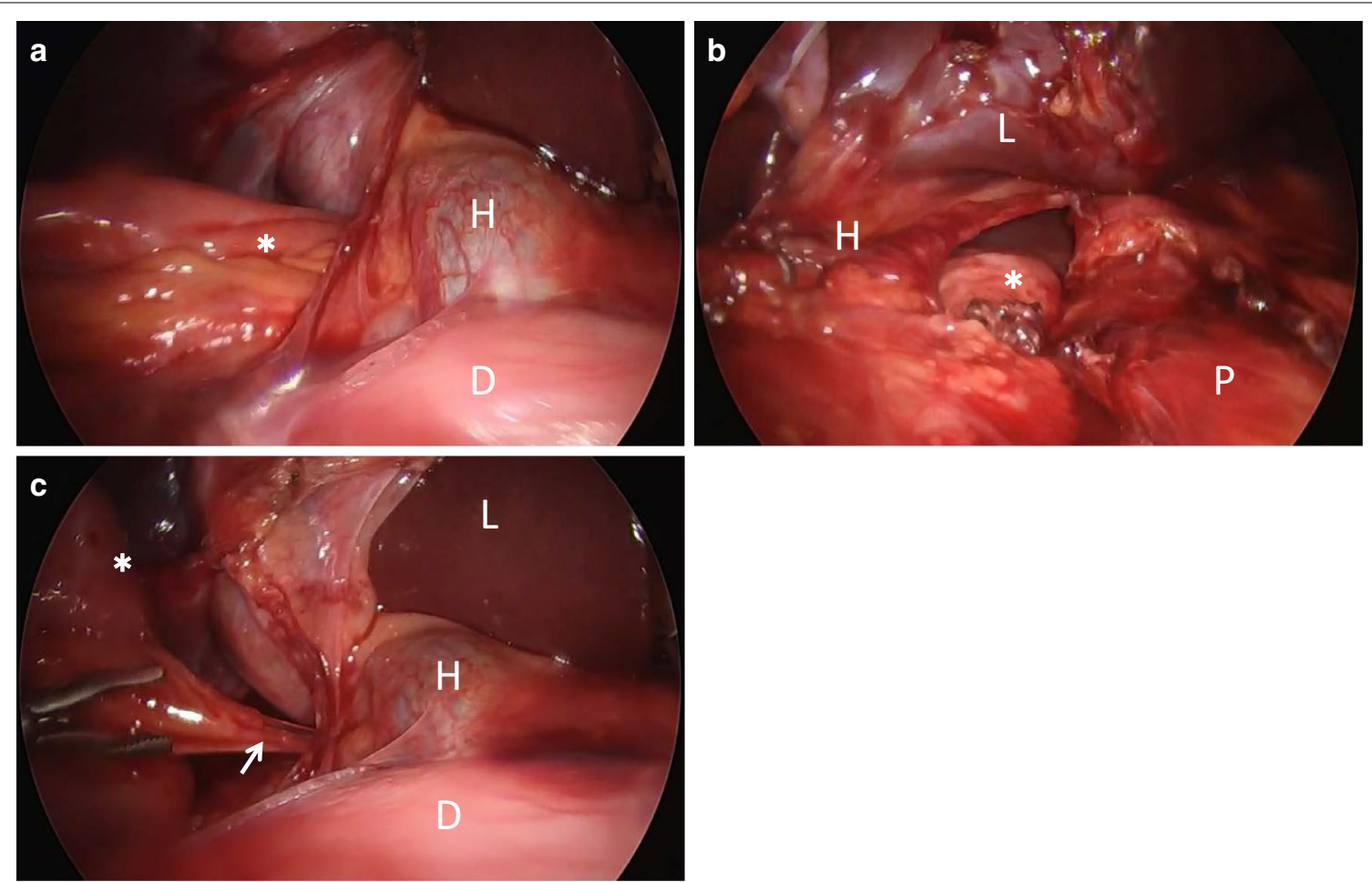

Fig. 3 Intraoperative laparoscopic views. a Small bowel $\left(^{*}\right)$ herniated through the foramen of Winslow. The bowel dilation reduced with the effect of the nasal tube before surgery. Due to adhesion between intra-omental tissue and herniated bowel, the herniated bowel was difficult to pull out from the foramen of Winslow. $\mathbf{b}$ The view shows the lesser sac opened by incising the lesser omentum. $\mathbf{c}$ The arrow shows one of the adhesions between the intra-omental tissue and herniated bowel. Duodenum, hepatoduodenal ligament, liver, and pancreas are labeled D, $H, L$, and $P$, respectively 


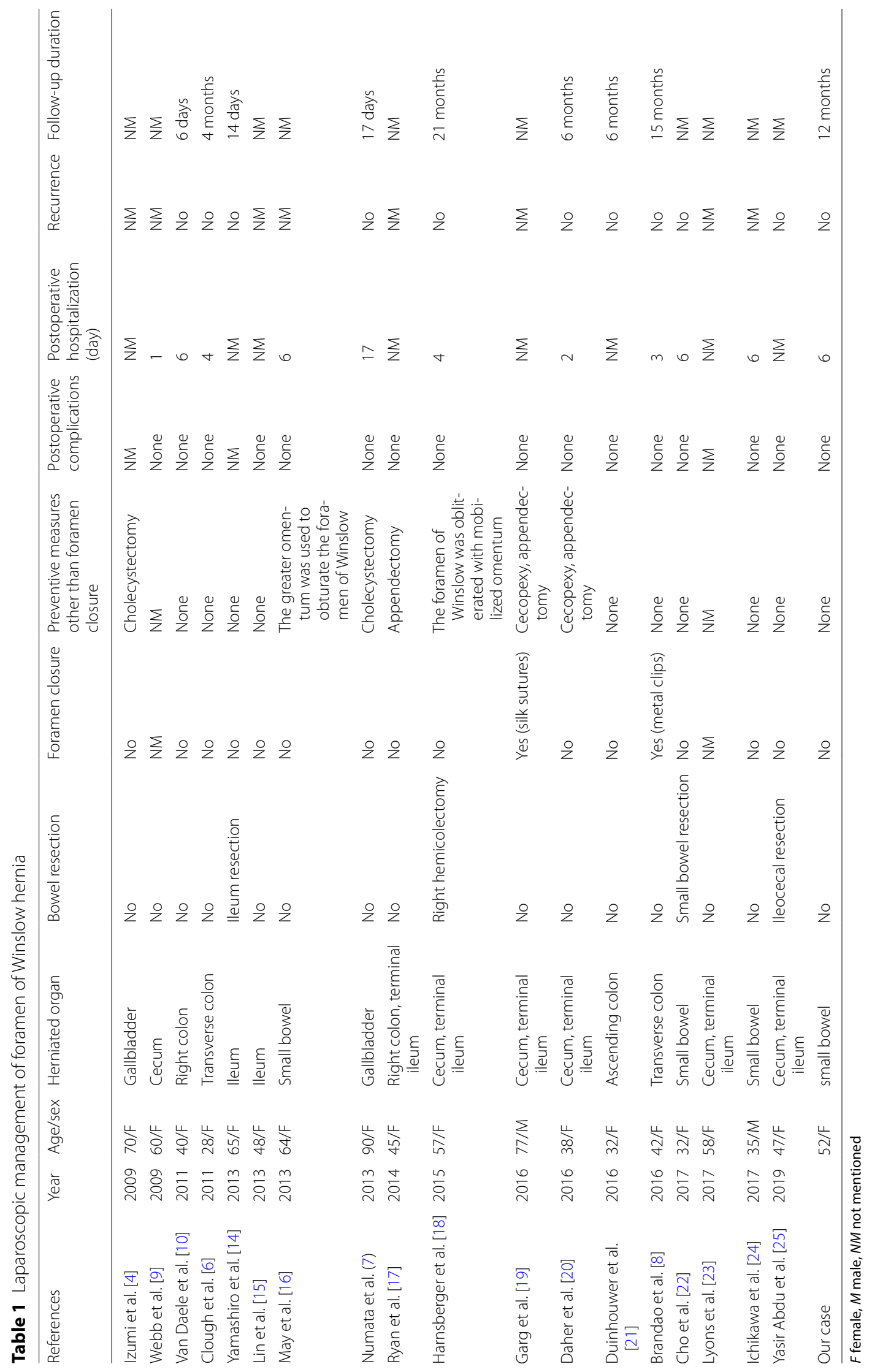


FWH caused by uterine fibroids. The causal correlation between large uterine fibroids and FWH remains unclear. In addition to the increase in the intra-abdominal pressure, large uterine fibroids may have pushed the small bowel out towards the upper abdomen, leading to FWH. The fact that there were some adhesions between the intra-omental tissue and the herniated bowel suggests that the small bowel, which was pushed out by large uterine fibroids, protruded through the foramen of Winslow for a long time.

Uterine fibroid is the most common type of tumor that grows in the uterus and presents with various clinical symptoms, such as heavy menstrual bleeding, iron deficiency anemia, infertility, pelvic pain, and pelvic masses [12]. For asymptomatic uterine fibroids, no intervention or further investigation is required. In contrast, for symptomatic patients, interventions (i.e., myomectomy, hysterectomy, uterine-artery embolization, or hormone therapy) are selected according to their inclinations (e.g., preserving fertility and their uterus) [13]. Because large uterine fibroids can cause internal hernias, treatment is necessary even in the absence of gynecologic symptoms.

Recent reports have revealed that laparoscopic surgery is feasible for FWH. To determine the characteristics of laparoscopic surgery for FWH, we performed a comprehensive literature search and identified 18 case reports in the field [4, 6-10, 14-25].

Table 1 outlines the characteristics of 19 cases including this case report. Although there were more female cases $(n=17)$ than male cases $(n=2)$, the incidence of FWH was higher in males than in females [2]. There were no cases of postoperative complications, including four cases wherein bowel resection was performed. In laparoscopic surgery, careful maneuver (i.e., gentle traction using atraumatic bowel graspers) is required when pulling the dilated bowel out of the foramen of Winslow [18]. Despite this, spontaneous hernia reduction was achieved at the time of surgery in some cases $[22,26]$. In this case, the successful bowel decompression supposedly contributed to decreasing the risk of bowel injury. Elective laparoscopic surgery after bowel decompression using a long intestinal tube may be suitable when there are no signs of bowel ischemia or peritonitis at the time of diagnosis.

Foramen closure was performed in only two cases (Table 1). The opening may be closed using a mesh for inguinal hernia or abdominal wall hernia. The efficacy of foramen closure in preventing the recurrence of FWH remains debatable. Because of the risk of injury to the bile duct, portal vein, and hepatic artery [21], some surgeons have obliterated the lesser omentum rather than closing the foramen $[16,18]$. Nevertheless, no recurrence was observed regardless of the performance of preventive measures. Furthermore, each predisposing factor has to be addressed to prevent a recurrence. In this case, treatment of the large uterine fibroids is the most important measure to prevent FWH recurrence.

\section{Conclusion}

We experienced a rare case of FWH due to large uterine fibroids. Laparoscopic surgery for FWH is considered to be a very effective treatment option not only because of its minimally invasive nature, but also its utility to perform delicate procedures (such as adhesiolysis) with a good magnified field of view. Treatment of the large uterine fibroids should be considered to prevent the recurrence of FWH rather than foramen of Winslow closure.

\section{Abbreviation \\ FWH: Foramen of Winslow hernia.}

\section{Acknowledgements}

We would like to thank Editage (www.editage.com) for English language editing.

\section{Authors' contributions}

$\mathrm{SH}$ was involved in patient care and wrote the first version of the manuscript $\mathrm{TI}$, SS and TO were involved in patient care and contributed to writing the manuscript. All authors read and approved the final manuscript.

Funding

This study was not funded.

Availability of data and materials

The datasets supporting the conclusions of this article are included in this paper.

\section{Declarations}

Ethics approval and consent to participate Not applicable.

\section{Consent for publication}

Written informed consent was obtained from the patient for publication of this case report and any accompanying images.

\section{Competing interests}

All of the authors declare no competing interests.

\section{Author details}

${ }^{1}$ Department of Surgery, Kobe City Medical Center West Hospital, 2-4, Ichibancho, Nagataku, Kobe, Hyogo 653-0013, Japan. ${ }^{2}$ Department of General Medicine, Nozaki Tokushukai Hospital, 2-10-5, Tanigawa, Daito, Osaka 574-0074, Japan.

Received: 20 January 2021 Accepted: 21 March 2021

Published online: 25 March 2021

\section{References}

1. Takeyama N, Gokan T, Ohgiya Y, Satoh S, Hashizume T, Hataya K, et al. CT of internal hernias. Radiographics. 2005;25(4):997-1015.

2. Osvaldt AB, Mossmann DF, Bersch VP, Rohde L. Intestinal obstruction caused by a foramen of Winslow hernia. Am J Surg. 2008;196(2):242-4.

3. Moris D, Tsilimigras DI, Yerokun B, Seymour KA, Guerron AD, Fong PA, et al. Foramen of Winslow hernia: a review of the literature highlighting the role of laparoscopy. J Gastrointest Surg. 2019;23(10):2093-9. 
4. Izumi J, Hirano H, Kasuya T, Odashima M, Kato T, Yoshioka H, et al. Gallbladder hernia into the foramen of Winslow: CT findings. Abdom Imaging. 2009;34(6):734-6.

5. Still RM, Scott R. Hernia through the foramen of Winslow in pregnancy. Obstet Gynaecol Br Commonw. 1967;74(6):939-40.

6. Clough AD, Smith GS, Leibman S. Laparoscopic reduction of an internal hernia of transverse colon through the foramen of Winslow. Surg Laparosc Endosc Percutan Tech. 2011;21(4):e190-1.

7. Numata K, Kunishi Y, Kurakami Y, Tsuchida K, Yoshida T, Osaragi T, et al. Gallbladder herniation into the lesser sac through the foramen of Winslow: report of a case. Surg Today. 2013;43(10):1194-8.

8. Brandao PN, Mesquita I, Sampaio M, Martins P, Daniel J, Davide J. Foramen of Winslow hernia: case report of a minimally invasive approach. J Surg Case Rep. 2016. https://doi.org/10.1093/jscr/rjw205.

9. Webb LH, Riordan WP. Internal herniation of the cecum through the foramen of Winslow. Am Surg. 2009;75(12):1252-3.

10. Van Daele E, Poortmans M, Vierendeels T, Potvlieghe P, Rots W. Herniation through the foramen of Winslow: a laparoscopic approach. Hernia. 2011;15(4):447-9.

11. MacDonald K, Hayward S, Nixon M, Holbrook A. Internal herniation through the foramen of Winslow during pregnancy: MR findings [corrected]. Abdom Imaging. 2011;36(3):318-20.

12. Vilos GA, Allaire $C$, Laberge PY, Leyland $N$. The management of uterine leiomyomas. J Obstet Gynaecol Can. 2015;37(2):157-78.

13. Manyonda I, Belli AM, Lumsden MA, Moss J, McKinnon W, Middleton LJ, et al. Uterine-artery embolization or myomectomy for uterine fibroids. N Engl J Med. 2020;383(5):440-51.

14. Yamashiro T, Ikeda H, Fujikawa A, Hashimoto K, Morimoto T, Miyakawa $\mathrm{K}$, et al. Internal hernia through the foramen of Winslow: the "narrowed portal vein" sign on abdominal CT. Emerg Radiol. 2013;20(3):247-50.

15. Lin WC, Lin CH, Lo YP, Liao YH. Rapid pre-operative diagnosis of ileal hernia through the foramen of Winslow with multi-detector computed tomography, enabling successful laparoscopic reduction. S Afr J Surg. 2013;51(1):35-7.

16. May A, Cazeneuve N, Bourbao-Tournois C. Acute small bowel obstruction due to internal herniation through the Foramen of Winslow: CT diagnosis and laparoscopic treatment. J Visc Surg. 2013;150(5):349-51.
17. Ryan J, Jin S, Frank J, Jacobs R. Internal herniation of the caecum through the foramen of Winslow. ANZ J Surg. 2014;84(1-2):95-6.

18. Harnsberger CR, McLemore EC, Broderick RC, Fuchs HF, Yu PT, Berducci $M$, et al. Foramen of Winslow hernia: a minimally invasive approach. Surg Endosc. 2015;29(8):2385-8.

19. Garg S, Flumeri-Perez G, Perveen S, DeNoto G. Laparoscopic repair of foramen of Winslow hernia. Int J Angiol. 2016;25:64-7.

20. Daher R, Montana L, Abdullah J, d'Alessandro A, Chouillard E. Laparoscopic management of foramen of Winslow incarcerated hernia. Surg Case Rep. 2016;2(1):9.

21. Duinhouwer LE, Deerenberg E, Rociu E, Kortekaas RT. Herniation of the colon through the foramen of Winslow-A case report. Int J Surg Case Rep. 2016:24:14-7.

22. Cho HG, Kang J. Spontaneous reduction of small bowel herniation through the foramen of Winslow: importance of a timely approach. Ann Surg Treat Res. 2017;92(2):113-6.

23. Lyons R, Sayles J. Laparoscopic reduction of a foramen of winslow internal hernia causing transaminitis. Am Surg. 2017;83(7):e238-9.

24. Ichikawa Y, Kanazawa A, Dan N, Ishikawa S, Hagi T, Mizojiri G, et al. Case of ileal herniation through the foramen of Winslow diagnosed preoperatively by CT and treated with laparoscopic surgery. Asian J Endosc Surg. 2017;10(3):328-30.

25. Mahnashi YA, Alshamrani AM, Alabood MA, Alzahrani AM, Sairafi RA. Laparoscopic management of cecum and ascending colon hernia through the foramen of Winslow. J Surg Case Rep. 2019. https://doi.org/10.1093/ jscr/rjz026.

26. Deschner BW, Schwulst SJ. Spontaneous reduction of acute cecal herniation through the foramen of Winslow. J Surg Case Rep. 2018. https://doi. org/10.1093/jscr/rjy236.

\section{Publisher's Note}

Springer Nature remains neutral with regard to jurisdictional claims in published maps and institutional affiliations.

\section{Submit your manuscript to a SpringerOpen ${ }^{\circ}$ journal and benefit from:}

- Convenient online submission

- Rigorous peer review

- Open access: articles freely available online

- High visibility within the field

- Retaining the copyright to your article

Submit your next manuscript at springeropen.com 